\title{
COMMENTARY
}

\section{Towards solving enigmas in electrical injury}

\author{
Christopher Andrews* \\ See related research by Park et al., http://ccforum.com/content/16/1/R25
}

\begin{abstract}
The paper by Park and colleagues in the previous issue of Critical Care highlights vascular changes in electrical injury and finds them to be relatively longlasting and significant. This finding is consistent with long-lasting disability seen clinically in electrically injured patients. Furthermore, the authors report that the changes seen in the shocked part of the body are accompanied by similar changes that are measurable in other parts of the body but that are not involved with electric current. This latter finding is of significant importance. A psychological syndrome - consistent and predictable - exists following an electrical injury. The causation is enigmatic. Recent psychiatric research indicates the importance of circulating cortisol and brain-derived neurotrophic factor (BDNF), which causes loss of hippocampal volume, in the genesis of depression. This psychiatric research has stimulated a speculative theory of the genesis of the psychological effects of electric shock. The paper by Park and colleagues is circumstantial support for the possibility that such a process is real and available.
\end{abstract}

\section{Introduction}

This writer was most interested to see the paper by Park and colleagues [1] in the previous issue of Critical Care. It represents a useful addition to the theory of electrical injury and tends to support speculation that has recently been advanced in regard to causation of the injury.

Consequences of electrical injury have always been enigmatic. Whereas the magnitude and pathway of the current can be predicted fairly readily and descriptions of the damage that occurs can be given, the tissue and biochemical changes that underlie much of the symptomatology are very poorly understood. Furthermore, causes of the long-term consequences of the injury have not been elucidated.

${ }^{*}$ Correspondence: chris.a@pobox.com

Mount Ommaney Family Clinic, Dandenong Road, Mount Ommaney, Queensland 4074, Australia

\section{Electrical injury}

Two groups of findings characterize the injury. Firstly, physical findings of pain, paresthesia, weakness, and easy fatigability are seen in the limbs affected by the passage of current. The easy fatigability is especially problematic - 'I haven't got the stamina I used to; I use the limb for a while, and then pay for it for days'. Typically, patients are referred to neurologists, but gross testing is usually normal. Neurologists most often conclude that there has been no neurological injury and a number, therefore, will say that there has been no injury at all. This grossly disadvantages patients, and the present author has wondered whether the site of injury, possibly at the neuromuscular junction or the sensory nerve terminal, is too fine to be demonstrated by gross testing. Secondly, there is a very commonly and consistently reported syndrome of long-lasting psychological disability [2-7]. It is this disability that can be the most distressing and the most limiting for a patient [8].

\section{The enigma of causation}

The enigma, especially for the psychological component, is that there seems to be a production of symptoms, in this case arising from the brain, quite remote from the passage of current. How injury in one part of the body can affect - quite organically - another part, including the brain, is an enigma.

The Critical Care paper refocuses attention on vascular abnormalities and demonstrates significant and longlasting abnormalities in vascular function. The genesis of these, it seems, centers on the vascular endothelium and damage to it. It is not quite clear, though, just what is involved - the endothelium or perhaps the nerva vasorum or indeed other structures. The vascular abnormalities are, in themselves, important as far as the first group of symptoms is concerned. One hopes to see further work in derived areas. Certainly, research on any changes in the results could take into account any change with significant exercise, and this may shed light on the fatigability mentioned above. Also, more identification of the particular vasoactive mediators of the vascular findings would be important. The physiology of the change in reactivity would readily assist and may lead us to a means of relieving it. 
But further observations made in the paper are interesting. In particular, the observation that the opposite limb was partially affected in the same way as the shocked limb is a fascinating finding and is perhaps of fundamental importance.

\section{Causation in electrical injury}

This writer has speculated on the possible causation of remote injuries, especially the influence on the brain and cerebral function, with the psychological symptoms in mind. The author has speculated on possible causative mechanisms and these may be many. The major mechanism might be, for example, a neurohumoral mechanism, in which the injured part or the injury process causes peripheral release of some neuroactive substance, which in turn acts on the brain. Or the major mechanism may be a reverse conduction mechanism. It is known that peripheral activation of pain receptors activates a complex set of interactions at the spinal cord level (turning acute pain into a chronic pain syndrome in which 'pain is the disease' rather than its cause), and reverse conduction superiorly via the cord to the brain may exist. No doubt, there may be several other mechanisms.

\section{Psychiatric findings}

Solving this enigma has not been attempted. One thought [9] invoking the release of humoral substance(s) has been advanced, bearing in mind recent psychiatric research indicating the importance of cortisol and brain-derived neurotrophic factor (BDNF) in the genesis of, in particular, traumatic depression [10]. Consequent loss of hippocampal volume is seen in depression [11-14], and there is some evidence of this finding specifically in electrical injury [15].

The finding of vascular reactivity, more general than just within the shocked limb, may add some support to a neurohumoral mechanism. Although the finding is mentioned only in passing, the present writer finds it to be of significance. One might hope to see further research that extends the present study and searches for the substance concerned and its mechanism of action. In addition, any correlation with hippocampal size in relation to the shock - as well as possibly other cerebral changes - would be of great interest. This writer has indeed used the term post-electric shock syndrome to describe the constellation that is seen. The incorporation of the syndrome into the Diagnostic and Statistical
Manual of Mental Disorders would be satisfying. It may be that we are moving closer to an explanation.

\section{Conclusions}

The paper by Park and colleagues [1] is to be commended, not only for its findings but also for the pointers it gives to further important research.

\section{Competing interests}

The author declares that he has no competing interests.

\section{Published: 5 March 2012}

\section{References}

1. Park K, Park W, Kim M, Kim H, Kim S, Cho G, Choi Y: Alterations in arterial function after high-voltage electrical injury. Crit Care 2012, 16:R25.

2. Janus TJ, Barrash J: Neurologic and neurobehavioral effects of electric and lightning injuries. J Burn Care Rehabil 1996, 17:409-415.

3. Pliskin NH, Ammar AN, Fink JW, Hill SK, Malina AC, Ramati A, Kelley KM, Lee RC: Neuropsychological changes following electrical injury. J Int Neuropsych Soc 2006, 12:17-23.

4. Primeau M, Engelstatter GH, Bares KK: Behavioral consequences of lightning and electrical injury. Semin Neurol 1995, 15:279-285

5. van Zomeren AH, ten Duis HJ, Minderhoud JM, Sipma M: Lightning stroke and neuropsychological impairment: cases and questions. J Neurol Neurosurg Psychiatry 1998, 64:763-769.

6. Andrews CJ: Further documentation of remote effects of electrical injuries, with comments on the place of neuropsychological testing and functional scanning. IEEE Trans Biomed Eng 2006, 53:2102-2113.

7. Morse MS, Berg JS, ten Wolde RL: Diffuse electrical injury: a study of 89 subjects reporting long-term symptomatology that is remote to the theoretical current pathway. IEEE Trans Biomed Eng 2004, 51:1449.

8. Cooper MA, Andrews CJ: Disability, not death, is the issue in lightning injury. In International Conference on Lightning and Static Electricity. Seattle, WA: Boeing; 2005.

9. Andrews CJ: The origin of remote symptoms in electrical and lightning injuries: an attempt at explanation and a hypothesis for testing. Journal of Lightning Research, in press.

10. Alexander N, Osinsky R, Schmitz A, Mueller E, Kuepper Y, Hennig J: The BDNF Val66Met polymotphism affects HPA-axis reactivity to acute stress. Psychoneuroendocrinology 2010, 35:949-953.

11. Bremner JD, Narayan M, Anderson ER, Staib LH, Miller HL, Charney DS: Hippocampal volume reduction in major depression. Am J Psych 2000, 57:115-118.

12. Sheline $Y$, Wang $P$, Gado M: Hippocampal atrophy in recurrent major depression. Proc Nat Acad U S A 1996, 93:3908-4003.

13. Videbach P, Ravnkilde B: Hippocampal volume and depression: a metaanalysis of MRI studies. Am J Psychiatry 2004, 161:1957-1966.

14. Czéh B, Michaelis T, Watanabe T, Frahm J, de Biurrun G, van Kampen M Bartolomucci A, Fuchs E: Stress induced changes in cerebral metabolites, hippocampal volume, and cell proliferation are prevented by antidepressant treatment with tianeptine. Proc Nat Acad Sci U S A 2001, 98:12796-12801.

15. Kurtulus A, Acar K, Adiguzel E, Boz B: Hippocampal neuron loss due to electric injury in rats: a stereological study. Leg Med (Tokyo) 2008, 22:2671-2675.

doi:10.1186/cc11209

Cite this article as: Andrews C: Towards solving enigmas in electrical injury Critical Care 2012, 16:117. 